\title{
Um puro animal
}

\section{Constança Carvalho Homem}

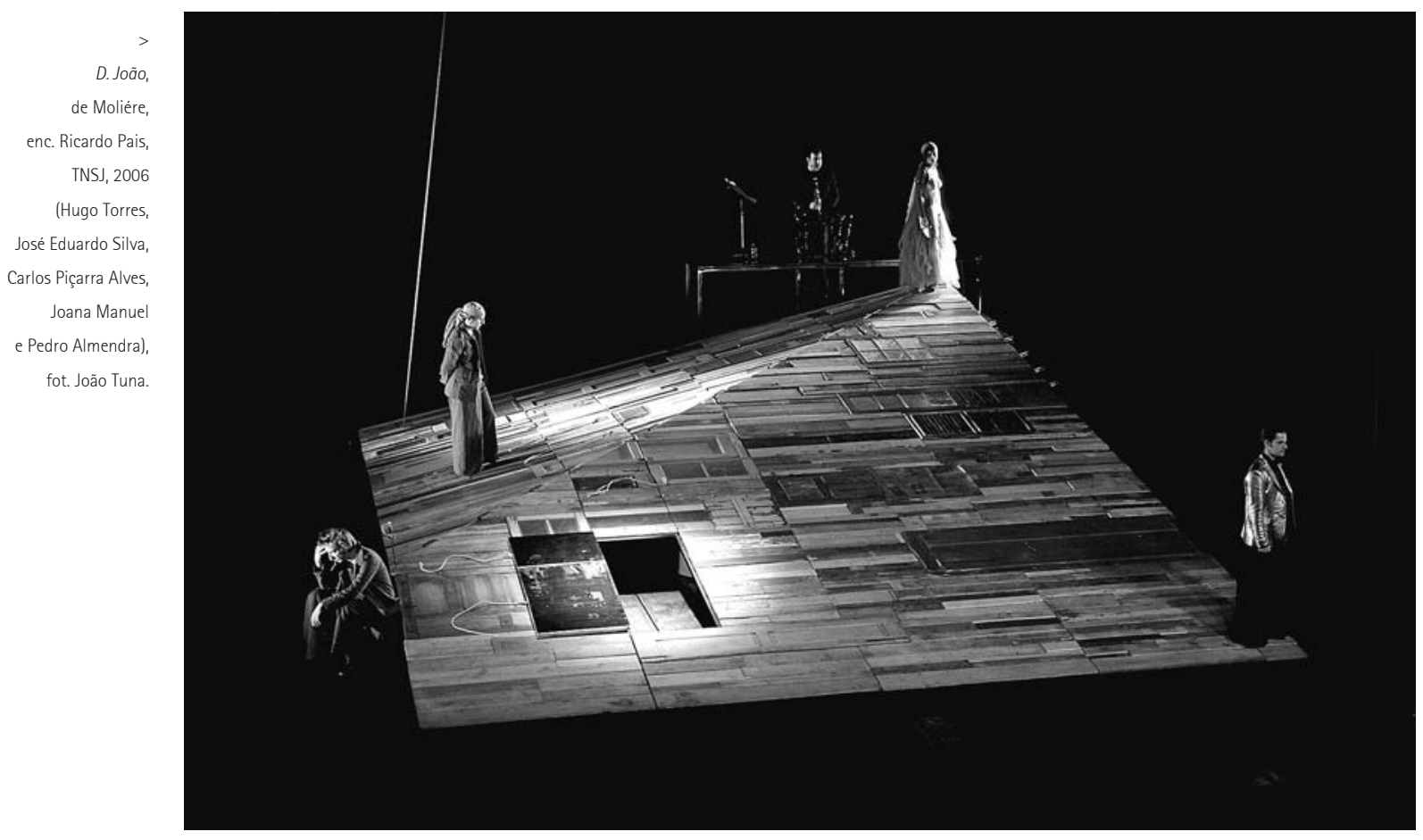

Título: D. João (Dom Juan ou le Festin de Pierre, 1665). Autor: Molière. Tradução: Nuno Júdice. Encenação: Ricardo Pais. Cenografia: João Mendes Ribeiro. Figurinos: Bernardo Monteiro. Desenho de som: Francisco Leal. Desenho de luz: Nuno Meira. Desenho de lutas: Miguel Andrade Gomes. Improvisações musicais: Carlos Piçarra Alves, sobre temas de Vitor Rua, Maurice Ravel e Rahul Dev Burman. Interpretação:António Durães, Hugo Torres, Joana Manuel, João Castro, João Merino, Jorge Mota, José Eduardo Silva, Ligia Roque, Marta Freitas, Paulo Freixinho, Pedro Almendra e Carlos Piçarra Alves (clarinetista). Produção: Teatro Nacional S. João. Local e data de estreia: TNSJ, Porto, 16 de Fevereiro de 2006.

0 regresso de $D$. João ao palco que originalmente o acolheu pontua de forma impressiva o mês de Abril na cidade do Porto. Em primeiro lugar, porque há um torpor de compasso de espera que antecede a trigésima edição do FITEI, evento que habitualmente concentra uma selecção relevante de teatro ibérico e sul-americano, e para o qual parte das companhias locais reserva as suas estreias; em segundo lugar, porque este $D$. João traz consigo o lastro feliz de uma viagem a Itália caracterizada pelo aplauso manifesto da crítica e do público. Rever $D$. João na sua segunda volta foi não só um prazer como a confirmação de uma convicção em latência: a de que este é um espectáculo maior.

0 texto de Molière oferece uma leitura peculiar e de raiz afastada da maior parte das apropriações do mito donjuanuesco, cujo paradigma foi firmado por Tirso de Molina, com El Burlador de Sevilla y convidado de piedra. Há, por um lado, uma reduzida incidência no potencial erótico da personagem, relegado para segundo plano em relação à sua "carta de intenções"; por outro lado, o malfeitor que Esganarelo tanto apregoa, em cena, protagoniza apenas uma sequência de malogradas tentativas de sedução, sequência a que o encenador Giorgio Barberio Corsetti chamou a "série negra" da peça (Benhamou 2006: 10). 0 cerne do texto é, efectivamente, o exercício de retórica através do qual $D$. João ludibria as suas vítimas, sejam elas mulheres, os defensores dessas mulheres, os credores ou o próprio pai. 0 Manual de Leitura que acompanha o espectáculo contém contribuições várias que concorrem para resolver o enigma da assunção da "profissão de hipócrita". Nuno Júdice, a quem devemos uma belíssima tradução, refere a "incapacidade de se fixar num amor, vizinha da impotência" (Júdice 2006: 4), ideia que Ricardo Pais prolonga: "Porque eu estou absolutamente convencido de que ele é um péssimo amante. Será um fantástico sedutor mas um péssimo amante, ninguém fica realmente satisfeito com ele" (Pais 2006: 18). Por sua vez, Anne-Françoise Benhamou escolhe a via psicanalitica para 


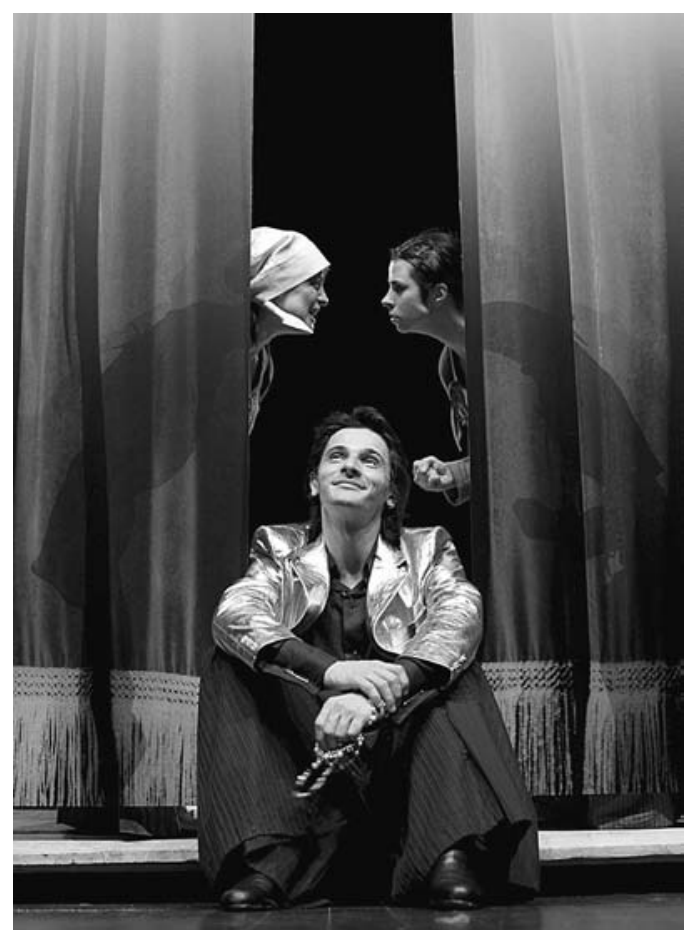

caracterizar a motivação do protagonista: "Os neuróticos não querem livrar-se da sua neurose; e a grande característica psicológica das personagens de Molière é a sua total ausência de redenção: aconteça o que acontecer (geralmente uma data de catástrofes), nada os modifica, nada os faz mudar. Saem da peça exactamente como entraram, a neurose não é corrigivel" (Benhamou 2006: 10). Seja qual for a perspectiva preferencial, estamos perante uma encenação que sublinha a inconstância e a obstinação através de um esquema de movimentos rigoroso e do privilégio à rápida transição entre cenas. É possivel, em comédia, tender-se para o abismo? Molière e Ricardo Pais esclarecem: dizem que é.

Devo também referir uma outra caracteristica textual que a encenação evidencia de forma impar: a alternância de registos. Não há dúvida de que este $D$. João é um objecto heteróclito, mas foi tecido de tal forma que o trágico e o cómico transparecem com a mesma verosimilhança. Deste modo, os momentos de desafio à autoridade paterna e divina, momentos de hybris que alargam o horizonte de expectativas da comédia, são tão convincentes quanto as prédicas do senso comum à "santo de pau carunchoso" de Esganarelo. Mas onde haveria, porventura, um maior grau de risco, houve também, porventura, o maior grau de sucesso. A introdução do falar das Caxinas como equivalente ao patois que Molière empregou suscita no público um misto de familiaridade e de alienação face a um tão particular emprego da língua. A versão final do enunciado resulta da combinação entre a reescrita do texto, feita por José Coutinhas, e a reconstituição fonética criteriosa de João Veloso, a partir de gravações recolhidas para o efeito. Os diálogos entre Pierrot e Carlota foram, sem margem para dúvida, os que provocaram as mais maciças convulsões de riso. Creio que os protestos amorosos de um Pierrot inseguro por si só não teriam obtido esta adesão: foram precisamente 0 dialecto caxineiro e a consequente desautomatização face a esse dialecto os grandes responsáveis pela eficácia destas cenas. Por outro lado, perante o contraste entre a norma usada por D. João e o dialecto falado por Carlota, verificouse um outro fenómeno imediatamente reconhecivel: o de hipercorrecção. Foi neste contexto que, para gáudio do público, houve uma total interpenetração dos registos e que D. João coroou o seu discurso com um "Dá cá um veijinho!".

Não é possivel saber-se até que ponto uma contingência estrutural, a condição de ser "poupadinho" a que Ricardo Pais alude, com ironia, na mensagem introdutória, deu lugar a um tamanho rasgo, mas, de facto, o dispositivo cénico concebido por João Mendes Ribeiro serviu genialmente este espectáculo, e outros dois ainda: Fiore Nudo, a partir de Don Giovanni, de Mozart e Da Ponte, e a leitura encenada de Frei Luís de Sousa, de Almeida Garrett.

\section{João, \\ de Moliére, enc. Ricardo Pais, TNSJ, 2006 (Ligia Roque, Pedro Almendra e Marta Freitas), fot. João Tuna}


É uma estrutura em aparência e funcionamento simples, que os próprios actores manipulam, mas que permite múltiplas variações em termos de relevo, volume e profundidade. A imagem da folha de papel, que João Mendes Ribeiro refere como base conceptual para o trabalho, é perfeitamente visivel nas virtualidades e na maleabilidade que este objecto oferece. 0 inusitado da abertura de um alçapão, uma entrada em cena a deslizar ou o despontar de uma cabeça onde menos se espera são efeitos que o cenário possibilita e que concorrem para a comicidade do espectáculo. Por outro lado, no momento que antecede o confronto entre D. Alonso e D. João, que constitui um prenúncio de xeque-mate, o palco perde 0 seu vinco original e estende-se em rampa, como um tabuleiro de xadrez. Ora, raras vezes vi em cena uma tão conseguida aliança entre forma e função, um tão grande entendimento entre acção, actores e cenário. De facto, e para citar apenas alguns dos vértices da carreira recente de Ricardo Pais, A Salvação de Veneza, Madame e Hamlet por exemplo, são espectáculos que fazem parte das minhas memórias formativas, mas que apreciei com certa reserva por me parecerem vítimas de uma qualquer constrição plástica. À distância de alguns anos, identifico essa constrição com um traço do estilo do encenador, uma tendência para a saturação, ou por "sobre-adereçar" a cena ou por "sobre-enfatizar" o acessório, que aos meus olhos impedia o ressoar limpido da interpretação. É evidente que este "sobre-" é de pessoal e dificil demarcação, mas a Castro foi, talvez, o espectáculo em que primeiro, e mais nitidamente, caiu essa estética do excesso. Os figurinos de Bernardo Monteiro, pautados pela escolha de materiais leves, menos nobres mas mais orgânicos, contribuíram igualmente para a fluidez da cena. Creio que parte da desenvoltura de $D$. João se prende com a economia e com o crivo da selecção dos elementos cénicos, o que resulta, a meu ver, num espectáculo extremamente limpo e sem ruído ou, nas palavras de António Maria Feijó, numa "forma próxima da levitação" (Feijó 2006: 18).

Do ponto de vista da interpretação, o meu elogio recai

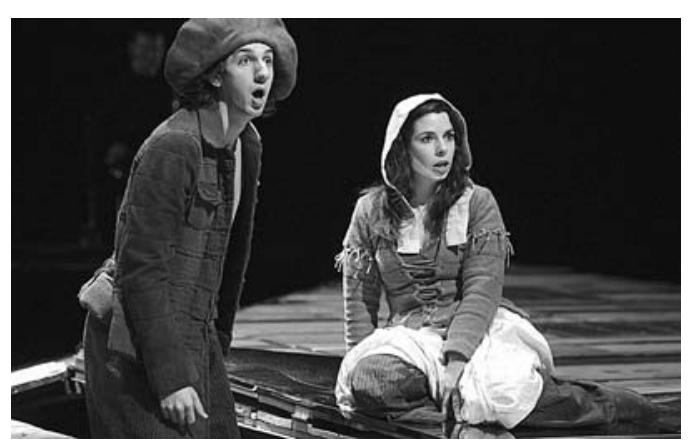

sobre alguns dos mais jovens membros do elenco. $\dot{E}$ obrigatório começar por destacar o Esganarelo de Hugo Torres, que se afirma aqui como um excelente actor de comédia. Impertinente e veloz, supersticioso e medricas na medida certa, o intérprete dá voz e corpo justamente àquilo que Esganarelo mais critica no amo, a sua natureza dúplice. Registo também o trabalho excepcional de João Castro e Marta Freitas, Pierrot e Carlota respectivamente, que amansaram com mestria o caxineiro, comprovando que a aposta na pesquisa colaborativa foi mais que ganha. Finalmente, refiro a interpretação comedida e competente de Pedro Almendra como D. João, cuja insaciabilidade transpareceu sem recurso a lugares-comuns.

A banda sonora é outro dos trunfos do espectáculo, sobretudo graças à participação de Carlos Piçarra Alves. 0 clarinetista encarna uma espécie de fauno montês, que comenta e amplifica a acção em tempo real. Mais do que um elemento de ligação entre cenas, a concepção de uma banda sonora que decorre com uma actuação ao vivo, e que se insinua em permanência, foi um factor essencial para a criação de uma atmosfera.

Por todos estes motivos, a reposição de $D$. João merece a minha maior alegria. Resta-me desejar que bons ventos propiciem uma digressão mais alargada e um reconhecimento generalizado do claro valor deste trabalho, tanto no contexto da programação do Teatro Nacional de S. João, como no contexto da obra individual de Ricardo Pais.

\section{Referências bibliográficas}

BENHAMOU, Anne-Françoise (2006), "Uma carta dramatúrgica", trad. Regina Guimarães, in Manual de Leitura de D. João, Porto, TNSJ, pp. 10-11

JÚDICE, Nuno (2006), "A palavra e o mito", in Manual de Leitura de D. João, Porto, TNSJ, p. 4.

PAIS, Ricardo / FEIJÓ, António M. / CABRAL, Patricia, (2006), "Discursos sobre um tarado 'aditivo'", in Manual de Leitura de D. João, Porto, TNSJ, pp. 14-19. 